\title{
Editorial
}

\section{Should corticosteroid aerosols be used in severe chronic asthma?}

Corticosteroids play an important part in the treatment of severe chronic asthma. They are usually given in an individually determined maintenance dose. Since 1955 attempts have also been made to influence asthma by locally administered corticosteroids such as micronised powders, ${ }^{12}$ and more recently, since beclomethasone diproprionate and betamethasone valerate have become available, these substances have been used widely as aerosols in order to avoid the adrenal suppression and other side-effects associated with systemic corticosteroids.

In a large number of carefully organised studies of these aerosol drugs, patients with asthma of varying severity have been investigated, ${ }^{3-5}$ though the proportion of patients with severe asthma has been relatively small, and results have usually been reported not individually but as means. Most such studies have shown the drugs to be effective and in many of the patients who had been on oral systemic maintenance doses of prednisolone of less than $10 \mathrm{mg} / \mathrm{day}$, the addition of a steroid aerosol (usually $400 \mathrm{mcg}$ day) would lower the systemic maintenance dose by 5 to $7 \mathrm{mg}$, so that the patient could either stop it altogether or remain on minimal, and probably unnecessary, amounts below $5 \mathrm{mg} /$ day.

The disadvantage of many of these earlier trials was not only the lack of patients with severe asthma but also in some cases it was not clear that the amount of daily corticosteroid maintenance had been reliably established over a long period before giving the steroid aerosol. Without these data there remained some doubt as to the overall therapeutic value of the steroid aerosols. Fortunately, during the last few years, some further trials have included more severe asthmatics. The first of these included a report on a separate group of 117 patients maintained orally on more than $10 \mathrm{mg}$ of corticosteroid daily. ${ }^{6}$ These patients can be regarded as suffering from severe asthma. Only the means of their systemic maintenance doses before and after adding steroid aerosol are reported, and it must be assumed, therefore, that this group may have included patients with an established maintenance dose of just over $10 \mathrm{mg}$ as well as some taking close to $30 \mathrm{mg} /$ day. All the same, the addition of the steroid aerosol to the systemic dose permitted a lowering of the latter by only 5 to $6 \mathrm{mg} / \mathrm{day}$, a similar amount to that found in the earlier trials with mainly mild cases of asthma.

In a further trial a group of 34 asthmatics who had been well maintained on daily prednisolone between 4 and $32 \mathrm{mg}$ were studied for 80 weeks. ${ }^{7}$ The beclomethasone in daily amounts between 200 and $1800 \mathrm{mg}$ was added and the oral dose gradually diminished as long as the asthma did not become worse. This trial is the first in which each single patient is documented in detail. It was found that 15 of the 34 patients whose oral maintenance had been 8 to $10 \mathrm{mg}$ prednisolone could abolish their oral supply of the drug, but not all of them consistently. The senior author has informed me that nine of these 15 had to take supplementary prednisolone from tıme to time. Twelve of this group of 15 , all of whom can be classified as having mild asthma, had received between 200 and $800 \mathrm{mcg}$ of steroid aerosol daily, the other three taking between 1000 and $1200 \mathrm{mcg}$. Of the remaining 19 patients, seven had required 12 to $14 \mathrm{mg}$ prednisolone as their maintenance dose, 10 required 16 to $18 \mathrm{mg}$, and one each 22 and $32 \mathrm{mg}$. The patients of this group received additional beclomethasone in a dose of 1200 to $1800 \mathrm{mcg} / \mathrm{day}$. This addition permitted a reduction of the oral maintenance dose by about $7 \mathrm{mg} /$ day. The clinical picture, judged from the frequency of the attacks, improved in 27 patients.

The latest of these trials concerns 54 patients who again are individually documented. ${ }^{8}$ They are divided into three groups. One group of seven patients with, apparently, severe asthma, had maintenance doses of $50 \mathrm{mg}$ (one), 27 to $31 \mathrm{mg}$ (five), or $20 \mathrm{mg}$ (one). Additional steroid aerosol reduced their oral prednisolone from an average of $31 \mathrm{mg}$ to $22 \mathrm{mg}$, that is by $9 \mathrm{mg}$; but if the one patient with the very high prednisone requirement of $50 \mathrm{mg} /$ day is left out as possibly doubtful, the average reduction of the systemic maintenance dose in this group of severe asthma was only by $7 \mathrm{mg}$. The second group of 29 patients with an 
initial prednisolone maintenance dose between 18 and $10 \mathrm{mg}$ (also severe asthma) varied greatly. The average corticosteroid dosage decreased from 15 to $8 \mathrm{mg}$, that is, again by $7 \mathrm{mg}$. The third group including 19 mild asthmatics with a systemic dosage of less than $10 \mathrm{mg}$ decreased their average doses of prednisolone from 8 to $3 \mathrm{mg}$, that is, by $5 \mathrm{mg}$.

The earlier as well as the later trials show that the milder forms of asthma which remain stable with low maintenance doses of oral corticosteroid (less than $10 \mathrm{mg} /$ day) can usually also be maintained by steroid aerosols alone in daily amounts between 400 and $800 \mathrm{mcg}$. With more severe asthma, when a systemic maintenance dose of $10 \mathrm{mg}$ prednisolone or more is necessary, this dose can be reduced by adding up to $1800 \mathrm{mcg}$ steroid aerosol/day, but it appears that the saving is not greater whether the patient has been on systemic doses of 12,20 , or even $30 \mathrm{mg} /$ day. On the contrary, the saving has been fairly constant at 5 to $7 \mathrm{mg} /$ day. The question therefore arises as to whether it is at all worth while to give the additional aerosol to these patients. But, before we go further, certain other considerations about the trials reported here seem necessary.

1 Before the attempt is made to replace the oral maintenance dose partly by aerosol, it must be absolutely certain that the patient is on his true maintenance dose-namely, on that amount of corticosteroid which he has required for long stretches of time in order to remain in a satisfactory condition. Ii such changes have been frequent in the past, as often happens, the patient is not a suitable subject for experiment, having no stable maintenance level. It must be feared that this precondition has not been fulfilled in all the previous trials, except perhaps in the Canadian one with its long observation period. ${ }^{7}$

2 Inhaling an aerosol from a pressurised bottle is a well-known and frequent experience for all severe asthmatics who, naturally, are accustomed to inhale bronchodilators. In many patients, this habit creates a conditional reflex, so that relief from dyspnoea may occur almost immediately, anticipating the pharmacological effect, and more so, if the smell or taste of the aerosol are always the same. This effect is important for the evaluation of steroid aerosols. It must be ensured in any study that relief reported by a patient and attributed to a steroid aerosol is genuine and not a placebo effect. The influence of such factors and of others of nervous origin have been discussed elsewhere. ${ }^{9}$
3 The frequent presence of mucus hypersecretion in asthma will necessarily have a strong but variable influence on the absorption of any aerosol. This may make a great difference with steroid aerosols, because here the amounts in micrograms absorbed count heavily, whereas this is not so with the strong beta-agonists, where experience shows that minimal amounts reaching the bronchial surface suffice. Apart from mucus hypersecretion, frequent intercurrent infections may decisively change the rate of absorption. Such interludes must be noted and evaluated.

4 The general experience with severe asthmatics who have been for years on oral corticosteriods does not show that a moderate decrease of adrenal function has severe disadvantages to health compared with the side-effects of other chronic medication. Moreover the effects on adrenal function of a small reduction in oral corticosteroids are not great. ${ }^{7}$

After consideration of these points, the following preliminary conclusions can be reached.

In mild asthma requiring a prednisolone maintenance dosage of under $10 \mathrm{mg}$ it is often possible to replace the oral steroids by an aerosol. In severe asthma, with a well-established and stable prednisolone dosage a reduction of this dosage can be achieved by the addition of a steroid aerosol. This reduction, however, usually does not exceed 5 to $7 \mathrm{mg} /$ day, whether the oral maintenance dose has been 10 or $30 \mathrm{mg}$ and more. As, therefore, the oral corticosteroid cannot be eliminated, it seems hardly worth while to complicate the simple and reliable oral treatment by the addition of a steroid aerosol, the effect of which is not decisive and, because of the changing local condition of the bronchi, uncertain.

This negative conclusion is based on a relatively small number of patients some of whom could not be regarded as being maintained on a stable oral corticosteroid dose. It must therefore be regarded as preliminary, to be confirmed or disproved by further investigations, in which all essential factors are taken into account.

H HERXHEIMER

9 Park Crescent

London

\section{References}

1 Foulds WS, Greaves DP, Herxheimer H, Kingdom LG. Hydrocortisone in the treatment of allergic conjunctivitis, allergic rhinitis and bronchial asthma. Lancet 1955; 1:234. 
2 Herxheimer $\mathrm{H}$, McAllen MK, Williams DA. Local treatment of bronchial asthma with hydrocortisone powder. $\mathrm{Br}$ Med J 1958; 2:762

3 Brown HM, Storey G, George WH. Beclomethasone diproprionate: a new steriod aerosol for the treatment of allergic asthma. Br Med J 1972; 1:585.

4 Cameron SJ, Cooper EJ, Crompton GK, Hoare MV, Grant IWB. Substitution of beclomethasone aerosol for oral prednisone in the treatment of chronic asthma. Br Med J 1973; 4:205.

5 British Thoracic and Tuberculosis Association. Report. Lancet 1975; 2:469.
6 Cooper EJ, Grant IWB. Beclomethasone diproprionate aerosol in treatment of chronic asthma. Q J Med 1977; XLVI:295-308.

7 Toogood JH, Baskerville J, Errington N, Jennings B, Chuang L, Lefcoe N. Determinants of the response of beclomethasone aerosols of various dosage levels: a multiple regression analysis to identify clinically useful predictors. J Allergy Clin Immunol 1977; 60:367.

8 Bascal E, Patterson R. Long term effects of beclomethasone diproprionate on prednisone dosage in the corticosteriod dependent asthmatic. J Allergy Clin Immunol 1978; 62:72. 